Filología y Lingüística XII(2): 7-23, 1986

\title{
BORGES Y EL LENGUAJE
}

\author{
Bernal Herrera Montero
}

\begin{abstract}
Thought about language becomes an obsession in Borges' literary works: poetry, essays and short stories. His ontology and his gnoseology are treated in a strict relationship to his linguistic criticism. For Borges, language is a problematic being because of its magic and aesthetic fundaments, because of its impossibility to catch and express facts and thought which happen simultaneously, and because of the many meanings of the words and the impossibility to control the connotations words have for different people. These are some of the aspects of Borges' thought about language dealt with in this article.
\end{abstract}

Es probable que el principal punto de partida que podamos encontrar en la reflexión borgeana lo sea su preocupación, constante y profunda, por el lenguaje. Dicho interés queda atestiguado en muchos lugares de su obra, como en "Un lector", donde confiesa:

"No habré sido un filólogo,

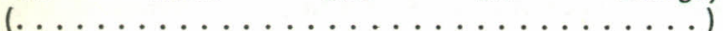
pero a lo largo de mis años he profesado la pasión del lenguaje (1)".

Este interés, esperable y natural en un escritor, alcanza en él caracteres de obsesión. No hay punto de su obra que no esté permeado por sus reflexiones sobre el lenguaje: su ontología, su gnoseología, están definidas y delineadas en íntima relación con su crítica del lenguaje. Porque para Borges, al igual que para los pensadores de las escuelas analíticas, éste se presenta como altamente problemático, y esto por muchos motivos. La raíz fundamentalmente mágica y estética del lenguaje; la imposibilidad de éste, siempre sucesivo, para captar y expresar el mundo simultáneo (problema planteado por Kant); la inevitabilidad, pese a lo anterior, del lenguaje en nuestro trato con el mundo; sus aspectos puramente mecánicos; la necesidad de expresar vivencias personales por medio de símbolos comunes; la polisemia de las palabras; la imposibilidad de controlar las connotaciones que tienen las palabras en las diversas personas; etc; son algunos de los problemas que al respecto plantea Borges. La cosa se complica aún más cuando vemos que estos problemas no sólo son inevitables sino, en alguna medida, hasta necesarios y deseables. Por ejemplo, siendo la polisemia un obstáculo para la exactitud del lenguaje, es una ventaja por la riqueza que permite. Siendo imposible discutir en detalle cada uno de los problemas planteados, me limitaré a resaltar los aspectos más importantes del pensamiento borgeano al respecto.

Borges parte del hecho de que todo lenguaje implica, de por sí, serios problemas. Lenguajes altamente racionalizados como el matemático o el discutido en "El idioma analítico de John Wilkins", no escapan a ello. Si esto es así en lenguajes construídos de la manera más racional posible, ¿qué no ocurrirá en los lenguajes corrientes? Ya en 1928 apunta: "Si las matemáticas (sistema especializado de pocos signos fundado $y$ gobernado con asiduidad por la inteligencia) entraban incomprensibilidades y son objeto permanente de discusión, ¿cuántas no oscurecerán el idioma, colecticio tropel de miles de símbolos, manejado casi al azar? Libros orondos -la Gramática y el Diccionario- simulan rigor en el desorden. Indudablemente, debemos estudiarlos y honrarlos, pero sin olvidar que son clasificaciones hechas después, no inventores o generadores de idioma (2)". Se apuntan aquí dos características que después surgirán con mayor claridad y fuerza: la arbitrariedad de todo orden lingüístico y la inevitabi- 
lidad de dicho orden si queremos que el lenguaje funcione como tal.

Una primera aproximación, ya que no solución, al problema del lenguaje consiste en afirmar el carácter fundamentalmente metafórico de éste. Borges empezará sosteniendo que todo lenguaje es metafórico, en tanto establece vínculos entre cosas, ideas y representaciones de manera arbitraria, por mucho que dichas arbitrariedades hayan sido aceptadas socialmente. Toda habla, toda escritura es metáfora, aún cuando gramaticalmente no pueda ser clasificada como tal. Hablar o escribir, nos dice Borges, es falsear, es metaforizar, es resignarse a ser Góngora. Recordemos de paso la temprana reducción del Borges ultraísta, rápidamente abandonada, de toda poesía a metáfora. Esta manera de enjuiciar el lenguaje, aunque con variantes, se mantendrá a lo largo de toda su obra, en la cual enfatiza el hecho de que el lenguaje es fundamentalmente un hecho artístico, una creación estética muy anterior a cualquier ciencia.

No implica ello que el lenguaje sea única y exclusivamente un hecho estético y mágico, sino que en su origen tuvo tal índole, lo que le imprime ciertas características que permanecerán en mayor o menor grado. Obviamente hay grandes diferencias entre este hipotético lenguaje original de cazadores y recolectores y los sofisticados $y$, al menos en apariencia, altamente racionalizados que utilizamos hoy en día. Borges se muestra totalmente consciente de esta evolución del lenguaje llegando a expresar una nostalgia por esta antigua fase, menos racional y reglamentada. Con todo, aún en los más modernos subsisten las características básicas del antiguo, por lo que considera posible su afloramiento si el usuario así se le propone: "La raíz del lenguaje es irracional y de carácter mágico. El danés que articulaba el nombre de Thor o el sajón que articulaba el nombre de Thunor no sabía si esas palabras significaban el dios del trueno o el estrépito que sucede al relámpago. La poesía quiere volver a esa antigua magia. Sin prefijadas leyes, obra de un modo vacilante $y$ osado, como si caminara en la oscuridad (3)".

Esta comprensión del lenguaje como metáfora, como hecho originalmente estético e irracional, tendrá muy profundas y variadas consecuencias. Menciono aquí dos. La primera, planteada ya en 1925 , es que si todo lenguaje es metafórico, ninguna de sus partes corresponde exactamente, y de ser así no lo sabemos, con lo que llamamos realidad. Mediante él ordenamos nuestra percepción de la realidad, percepción que tenemos de manera directa pero cuya expresión no siempre le corresponde. Afirmó por ejemplo: "El lenguaje es un ordenamiento eficaz de esa enigmática abundancia del mundo. Dicho sea con otras palabras: los sustantivos se los inventamos a la realidad (4)".

Borges concibió los sustantivos, al igual que Berkeley, Mauthner y los tlönianos, como abreviaturas o conjunciones de adjetivos. De la misma manera, si todo lenguaje es igualmente metafórico, prosa y poesía, literatura y filosofía estarán igualmente lejanos, o igualmente cercanos, de la realidad. No existe ningún tipo de lenguaje que de por sí garantice una mayor cercanía a la realidad. Como afirma Borges, ignoramos sí el universo pertenece a la literatura fantástica o a la realista. La segunda consecuencia, íntimamente ligada a la anterior, es lo que podría llamarse la indiferencia gnoseológica: ya que ningún lenguaje es, por sí mismo, más adecuado que los demás para captar y expresar el mundo, no habrá demasiada diferencia entre expresar nuestro pensamiento, por ejemplo, en forma literaria o filosófica, lo cual refuerza lo anteriormente dicho:

Se impone aquí una aclaración que habrá que tener presente a todo lo largo del trabajo: el lenguaje, en tanto fenómeno real y existente, es parte de la realidad total. Además, el lenguaje puede llegar a constituir en sí mismo, como veremos, una realidad superpuesta a la, Ilamémosla así, realidad no verbal. La diferenciación que se utilizará aquí a menudo entre lenguaje y realidad toma a ésta última únicamente en su sentido de realidad no verbal, y es una división metodológica y expositiva, por lo que no debe hacer creer en ningún momento que el lenguaje es considerado por Borges como una irrealidad, como algo fuera de la realidad. $\mathrm{Al}$ respecto ha dicho: "No creo que lo que yo escribo sea irreal, aunque no sé qué es la realidad y qué la irrealidad. Si yo pensara que todo es vano, que todo es un sueño en ese sentido... no escribiría tampoco (5)".

Por tanto, se utilizará aquí la palabra realidad en tres sentidos: realidad total, que abarcaría todo lo existente; realidad no verbal, que estaría constituida por todo lo existente no lingüístico; y realidad verbal, que denota al mundo lingüistico. Estoy totalmente consciente de la arbitrariedad que implica lo anterior, pero me parece preferible a cualquier otro procedimiento tal como utilizar otra terminología, crear neologismos, etc. Tomando en cuenta lo anterior, el uso del térmi- 
no no creará ninguna dificultad para la comprensión del trabajo. Aquellos casos en que el sentido no resulte suficientemente evidente, se aclarará para evitar confusiones.

Es de notar que aunque Borges ha mantenido esta concepción del lenguaje como hecho fundamentalmente estético y metafórico, su manera de reaccionar ante ella no ha sido igualmente invariable. En sus primeros libros de ensayos (de los que no ha permitido su reedición, siendo casi inaccesibles) propone ciertas reformas algo ingenuas, del lenguaje, con la idea de volverlo más exacto y eficaz. Entre otras cosas propuso derivar adjetivos, verbos y adverbios de los sustantivos; convertir los verbos neutros en transitivos y viceversa; emplear las palabras con mayor rigor etimológico; etc. Esto, junto a la denuncia de los aspectos puramente mecánicos del lenguaje; la esencial falsedad atribuída a conceptos tales como yo, tiempo, espacio, materia; la construcción de neologismos con intenciones puramente poéticas; etc; contribuiría en su opinión a depurar y enriquecer el lenguaje. Sin embargo, pronto llegó al convencimiento de que el problema no estaba en el lenguaje concreto utilizado sino en la naturaleza misma de éste, cualquiera que sea. Esto lo llevó a renunciar a sus anteriores pretensiones de reforma y a tratar, más bien, de sacar el máximo provecho del que le había tocado en suerte.

Podría creerse que se puede apuntar aquí una contradicción en el pensamiento de Borges. Si todo lenguaje es igualmente metafórico, igualmente útil como medio artístico e inútil como herramienta exacta de conocimiento, ino carece de fundamento su continua queja del español, idioma del que ha dicho que es más apto para la vanidad palabrera que para la expresión del pensamiento, lo que pareciera indicar que hay idiomas más exactos y eficaces? Alguno recordará además que él siempre se ha quejado de la pobreza de las letras hispánicas en contraposición, por ejemplo, a la riqueza de las inglesas y alemanas. Sin embargo, dicha contradicción es resuelta por el autor cuando afirma que el quejarse del español es lo lógico en alguien que tiene que expresarse en dicho idioma, suponiendo que si le hubiera tocado en suerte digamos, el alemán, su queja sería contra este último. Mientras Borges saca inmenso placer de sus lecturas en los varios idiomas que domina, sólo tiene que trabajar con el español, por lo que será de éste del único que conozca a fondo las deficiencias.
Hay otra observación, planteada por Rest en su excelente trabajo, quien apunta que Borges no parece estar consciente de lo paradójico del hecho de criticar el lenguaje con herramientas puramente lingüisticas. Su crítica al lenguaje mediante el lenguaje mismo, ¿hasta qué punto es válida? A lo anterior cabe contestar que una de las preocupaciones fundamentales del autor acerca del lenguaje es su inevitabilidad. Por muy deficiente que sea, nos dice, estamos condenados a usarlo si queremos pensar y expresar nuestro pensamiento. Yo plantearía más bien lo siguiente. Se nos dice que todo lenguaje es igualmente metafórico, y que las palabras aisladas carecen de significación. Sin embargo pareciera haber la creencia de que los adjetivos responden de manera más inmediata y directa a la realidad. No se cree, en una primera etapa, en la existencia real de los objetos denotados por los sustantivos, pero sí en la de las cualidades implicadas en los adjetivos y en la de las acciones implicadas en los verbos. Esto, que está en íntima relación con la temprana influencia que sobre Borges ejerciera el pensamiento de Berkeley, pareciera implicar una cierta inconsistencia. Hay en recordar aquí que para Borges el lenguaje es fundamentalmente capacidad de representación.

En un extenso ensayo incluido en su libro El idioma de los argentinos (1928), discute tres teorías respecto a los elementos constitutivos del lenguaje. Por un lado están los gramáticos, quienes consideran que cada palabra es portadora de sentido. A esto se opone aduciendo que las palabras, por sí mismas y en estado de aislamiento, carecen de sentido. El hecho de que a cada palabra no le corresponda necesariamente una idea es fácilmente observable, nos dice, tanto en el hecho de que en una frase o texto no hay tantas ideas como palabras como en la posibilidad de expresar una misma idea con diversas palabras. En cuanto a la teoría de Croce, de que son las frases las que poseen sentido, siendo ellas lo fundamental del lenguaje, es igualmente rechazada por Borges alegando que pueden encontrarse frases conteniendo más de una idea, frases que no contengan ninguna, frases de una sola palabra, etc.

Para él lo fundamental en un lenguaje será la representación, siendo ésta toda idea que sea susceptible de ser representada por parte del sujeto. Dichas representaciones pueden estar constituidas por una sola palabra o por muchas no siendo, por tanto, una categoría estrictamente gramatical sino más bien psicológica. Es por ello por lo que Borges medirá la riqueza de un idioma no 
por el número de palabras que contenga, sino por el número de representaciones que permite. Esto lo llevará a criticar la costumbre retórica de estar utilizando constantemente diversos sinónimos, lo que tras una falsa apariencia de riqueza oculta una real pobreza de los auténticos componentes del pensamiento: las representaciones.

Dentro del campo del lenguaje podemos notar claramente la fuerte influencia de tres autores en el pensamiento borgeano: Berkeley, Mauthner y Schopenhauer. En ellos ha encontrado argumentos y razones para su innata desconfianza del lenguaje, así como la creencia en sus profundas limitaciones. Tanto Berkeley como Mauthner atacaron la realidad de las ideas abstractas y la exactitud de los conceptos generales, y los tres vieron en el lenguaje una herramienta práctica pero tosca, que difícilmente permite expresar la riqueza de los objetos y experiencias individuales con todos sus detalles y particularidades. Vieron claramente que si se quería tener un instrumento útil, esto solo podía lograrse a cambio de un notable empobrecimiento de lo expresado. Todo ello es aceptado por Borges, quien luchará toda su vida para ir encontrando medios más exactos y ricos de expresión. La influencia de Berkeley y Schopenhauer en estos temas es perfectamente distinguible para todos los lectores que conozcan adecuadamente su pensamiento; en cuanto a la de Mauthner, por ser un autor virtualmente desconocido e inaccesible en español, es insustituible la obra de Arturo Echavarría Lengua y literatura de Borges, en donde hay una documentada sección destinada a su estudio.

Ya definida la idea rectora de las reflexiones borgeanas sobre el lenguaje, ¿qué encontramos en ellas? Borges empieza por tratar de aclarar la relación del individuo con el lenguaje. Aquí su opinión será que todo idioma es una creación colectiva, sobre la cual el individuo ejerce escaso control. Todo idioma, además, transmite una visión del mundo, un modo de sentir la realidad, que condicionará la nuestra propia. Un lenguaje es toda una tradición, y en él han ido depositándose infinidad de experiencias individuales $y$ colectivas que hacen que, lejos de ser un simple conjunto de símbolos, se constituya en una cosmovisión que se pasa de una generación a otra. En este sentido, un idioma es una memoria compartida, colectiva. Así como para él la memoria individual es, como veremos, elemento fundamental para la constitución y preservación de un yo coherente y continuo; de la misma manera esta memoria colectiva que es el lenguaje será lo que permita la constitución y preservación de una cultura. Toda creación lingüística es una creación cultural, social, que subsistirá en tanto sea preservada por el lenguaje.

Dicha creación, por ser colectiva y en buena parte inconsciente, no obedece a ningún plan racional y estructurado, por lo que en su desarrollo interviene copiosamente el azar. El individuo debe aceptar, si desea comunicarse, todo este caudal de representaciones que se le entrega durante la adquisición de un idioma. Todo intento realmente radical de innovación está en buena medida condenado al fracaso. "Cada lenguaje es una tradición, cada palabra, un símbolo compartido; es baladí lo que un innovador es capaz de alterar; recordemos la obra espléndida pero no pocas veces ilegible de un Mallarmé o de un Joyce (6)'".

Estamos marcados, de una u otra manera, por todos aquéllos que antes de nosotros han usado nuestro idioma; ignoramos en muchos casos de donde vienen las representaciones que manejamos cotidianamente. Prologando El oro de los tigres nos dice Borges: "En cuanto a las influencias que se advertirán en este volumen... En primer término, los escritores que prefiero -(...)-; luego, los que he leído y repito; luego, los que nunca he leído pero que están en mí. Un idioma es una tradición, un modo de sentir la realidad, no un arbitrario repertorio de símbolos (7)'”.

De lo expuesto se desprenden claramente dos características de todo lenguaje: su carácter supraindividual y tradicional, y el hecho de implicar una manera de percibir el mundo, una ordenación de éste. Respecto a la primera hay que hacer una observación: si bien es cierto que todo individuo, para poder utilizar y aprovechar adecuadamente el lenguaje debe mantenerse dentro de los límites que éste le marca, sería absurdo decir que no tenga ninguna influencia sobre él. En primer lugar, así como la tradición que hemos recibido ha sido forjada por quienes han vivido antes de nosotros, así nosotros podemos influir en la que recibirán quienes vengan después. Además, todo creador de importancia influye en la manera de percibir la tradición misma. Esto, que es planteado de la manera más clara en el ensayo "Kafka y sus precursores", implica que no sólo podemos influir en la tradición futura sino, en algún sentido, en la pasada. El hombre no es un agente inerte en manos de la tradición, sino que 
puede ayudar a moldear su pasado y su futuro.

En cuanto a la ordenación del mundo que nos es transmitida por el lenguaje, resulta claro que es ésta una de sus labores más importantes. Si no dispusiéramos de el lenguaje y todo lo que él implica: conceptos, clasificaciones, nombres, etc., el mundo perdería buena parte de su sentido y de su orden. Muchas de las principales características del lenguaje derivan de esta condición suya de ordenamiento del mundo. Siendo el lenguaje una especie de guía tendrá necesariamente dos características: una cierta arbitrariedad y una mayor simplicidad y rusticidad que el mundo mismo. Ambas características están íntimamente ligadas. Ya que no sería de utilidad un mapa, una guía del mismo tamaño y complejidad que la realidad misma (cf.: "Del rigor en la ciencia", en El hacedor) es claro se irán fijando, de manera más o menos arbitraria, los aspectos de la realidad que resulte más conveniente o necesario resaltar, con el lógico desmedro de otros. Así como toda explicación del mundo, todo sistema filosófico, nos dice Borges, no es más que la subordinación de los demás aspectos del mundo a uno sólo de ellos, todo lenguaje es una jerarquización, una clasificación del mundo, y al respecto nos afirma: "no hay clasificación del universo que no sea arbitraria y conjetural. La razón es muy simple: no sabemos qué cosa es el universo (8)".

En cuanto a la mayor simplicidad del lenguaje con respecto a la realidad, su necesidad es obvia: si el lenguaje fuera tan complejo como aquella, tal y como quería Funes, sería totalmente superfluo e innecesario.

Todo lenguaje es el resultado de infinitas relaciones del hombre con el mundo, consigo mismo y con los demás. Como producto de un inmenso esfuerzo de las generaciones a través del tiempo, se va fijando en un idioma una visión del mundo que nos es transmitida, estemos conscientes o no de ello. Todo lenguaje será siempre para Borges, como lo ha planteado Barrenechea en su clásico estudio, una interpretación y ordenación del universo, y no un simple reflejo de éste.

Lo anterior nos permite ubicar el pensamiento borgeano en el campo del nominalismo, tal y como lo hace Rest. Con respecto a la observación de éste de que el autor no siempre reconoce esta afiliación, recordemos que él nos ha dicho: "El nominalismo, antes la novedad de unos pocos, hoy abarca a toda la gente; su victoria es tan vasta y fundamental que su nombre es inútil. Nadie se declara nominalista porque no hay quien sea otra cosa (9)".

La función del lenguaje como portador de maneras de interpretar y sentir el mundo obliga a Borges, y a nosotros, a plantear lla relación entre lenguaje y pensamiento. Si muestra manera de sentir y de pensar el mundocestán en buena parte determinados por los mecanismos y categorías lingüísticas a nuestro alcance, ¿qué influencia tendrán estos sobre el pensamiento? La primera preocupación borgeana al respecto es la aparente contradicción entre el carácter personal del pensamiento y el público e impersonal del lenguaje, problema que ha suscitado en él diversas actitudes a través del tiempo.

En sus primeros libros de ensayos se queja de esta inevitable y empobrecedora necesidad de expresar nuestro pensar y sentir personal en un lenguaje impersonal que, a menudo, nos traiciona. Es casi imposible, nos dice, que en ese traslado no se pierdan muchos matices y aspectos de lo pensado y sentido por el sujeto, mientras que se adhieren otros que en más de un caso distorsionan lo que se ha querido comunicar. Recordemos que por esta misma época conservaba todavía la esperanza de que el individuo, mediante ciertas reformas, puede conseguir lenguajes más adecuados para la expresión de su pensamiento. Sin embargo, como se ha visto, tal esperanza es abandonada rápidamente, lo que obliga a un replanteamiento del problema. En primer lugar, se hace claro que si bien el lenguaje al transmitirnos una interpretación del mundo que las generaciones anteriores han ido elaborando $y$ fijando, condiciona en alguna medida nuestra forma de pensarlo, también lo es que sería totalmente imposible para cada sujeto elaborar por sí sólo, y sin ayuda del lenguaje, una interpretación de éste. O sea que el lenguaje, al mismo tiempo que condiciona, en buena medida posibilita nuestro propio pensamiento. Por otro lado es obvio que es este carácter de 'común' lo que posibita la existencia misma del lenguaje. Si no fuera así, no habría comunicación entre las personas, y aquél perdería casi todo su sentido.

El lenguaje nos transmite una gran cantidad de pensamientos y recuerdos de otros hombres, que nosotros utilizamos para relacionarnos con el mundo, para pensarlo. El hecho de que todo lenguaje implique una ordenación del mundo hace que éste sea mucho más que un puro caos sensorial. Además, la inevitabilidad del lenguaje es 
afirmada por Borges al decir: "el lenguaje es ya una tradición, es decir, una organización del mundo en ciertos conceptos. De modo que querer librarse de él es un absurdo (10)". Ya que es imposible e inconveniente pretender establecer un lenguaje totalmente propio, lo que queda es buscar los medios para, dentro del ya establecido, expresar de la manera más adecuada el sentir y el pensar personales. Por tanto no estoy de acuerdo con Lusky, quien interpreta la obra de Borges como una lucha continua contra las limitaciones impuestas al hombre por el carácter lingü ístico de su pensamiento, lo que implicaría la posibilidad de uno que, rompiendo con lo lingüístico, evitara dichas limitaciones. La lucha de Borges es por lograr formas de expresión que le permitan transmitir, con la menor distorsión posible, su pensamiento. Toda la obra de Borges atestigua los esfuerzos hechos en esta dirección. Sus escritos, como lo hace ver Yurkievich, nunca serán mecánicamente convencionales, sino que tratan de establecer las formas más adecuadas para transmitirnos las representaciones que desea dar a conocer. Nada más como ejemplo de lo anterior recordemos su esfuerzo por atenuar la sonoridad de las palabras en beneficio de un mayor énfasis en su significación. Con todo, el problema causado por la necesidad de expresar nuestros pensamientos y experiencias personales por medio de un lenguaje común, será sentido y planteado por Borges a través de toda su obra, apareciendo con toda claridad en cuentos como "El aleph" y "El congreso". Su posición tendrá tanto de aceptación ante la inevitabilidad y conveniencia del lenguaje compartido, como de queja por el necesario empobrecimiento y distorsión que ello causa. No pudiendo evitar su uso, tratará de manejar el lenguaje de manera tal que implique la menor distorsión posible.

Eso es, en el fondo, lo que hace todo escritor profundo, con lo que acaba construyendo algo a lo qué, en cierto sentido, se le puede llamar un lenguaje personal. Nos dice al respecto Echavarría Ferrari: "a partir de una concepción del lenguaje como un sistema arbitrario de símbolos que objetivamente nada tiene que ver con la realidad, de un sistema simbólico que tiende a despersonalizar a quien lo maneja (a negar la personalidad individual) y que arrastra consigo un caudal de tiempo colectivo e individual ajenos a quien se propone usarlo de manera creadora, Borges pasa a la constitución de un 'lenguaje' personal por medio de alusiones a otros textos y, sobre todo, a los suyos propios (11)".

Todo pensamiento estará siempre condicionado por el lenguaje, no hay pensamiento sin lenguaje. A su vez, no hay mecanismo lingüístico que no implique pensamiento. Borges, siempre tan interesado en la metáfora, nos dice: "Metaforizar es pensar, es reunir representaciones o ideas (12)". Si recordamos que todo lenguaje es metáfora, habrá que concluir que todo lenguaje es, en última instancia, pensamiento. Lo anterior tiene, no obstante, una excepción que es anotada por Borges: el lenguaje puramente mecánico. En cuentos como "La otra muerte" y "La noche de los dones", por ejemplo, se alude a narraciones que, a fuerza de repetirse, no parecen tener ya ningún significado para quienes las cuentan". Lo que se da es una mera repetición mecánica de un relato, sin que ello implique una actividad mental en concordancia con lo narrado. A fuerza de repetir mecánicamente la misma historia, esta pierde para quien la narra, no para quien la escucha, la capacidad de representación que originalmente tuvo. O sea, un relato que nace como cualquier otra actividad lingüistica de una actitividad intelectual, con el tiempo se transforma en una mera fórmula sujeta a repeticiones periódicas y mecánicas, que, sin embargo, tendrá para quien la oye por primera vez la misma capacidad de representación que tuvo originalmente para quien la narra. Así, no es que el lenguaje carezca de dicha capacidad, sino que el ejecutante no la actualiza. Lo mismo podría decirse de otros tipos de lenguaje que pueden ser utilizados de manera puramente mecánica, tales como las fórmulas protocolarias y de cortesía. Borges, siempre tratando de potenciar la significación y capacidad representativa del lenguaje, ha denunciado reiteradamente los aspectos puramente mecánico de éste.

Dadas las intimas relaciones entre lenguaje y pensamiento, habrá una estrecha concordancia entre ambos términos. Así, refiriéndose a Tlön, afirma: "Las naciones de ese planeta son -congénitamente- idealistas. Su lenguaje y las derivaciones de su lenguaje la religión, las letras, la metafísica- presuponen el idealismo. El mundo para ellos no es un concurso de objetos en el espacio; es una serie heterogénea de actos independientes. Es sucesivo, temporal, no espacial. No hay sustantivos (13)". Resulta difícil saber aquí si es el lenguaje el que determina la forma de ver el mundo, o si es al revés. Las profundas 
limitaciones que sobre el pensamiento establece el lenguaje se ejemplifican también en Tlön, donde los pensadores se ven imposibilitados de expresar adecuadamente una visión materialista del mundo.

Como vemos, es imposible separar el pensamiento de los mecanismos lingüísticos con que cuenta para su funcionamiento y expresión. Un ejemplo analizado por Borges son las consecuencias que tiene en el pensamiento de Zenón de Elea la admisión del concepto de infinito; otro lo encontramos en el siguiente texto: "La palabra problema puede ser una insidiosa petición de principio. Hablar de problema judio es postular que los judíos son un problema (14)".

Dentro de la visión borgeana el lenguaje posibilita $y$, simultáneamente, condiciona al pensamiento. Ambos factores de la relación han sido tratados por Borges. En cuanto al condicionamiento del pensamiento por parte del lenguaje éste tiene su raíz, fundamentalmente, en un hecho que no puede ser descuidado: la íntima relación entre las categorías lingüísticas y las de pensamiento: determinados mecanismos lingü ísticos suelen implicar modos igualmente determinados de pensamiento. La inexistencia de los sustantivos en Tlön impide pensar a sus habitantes en la existencia de cosas permanentes y con realidad propia. En la vida real, esta idea de la íntima relación entre ambos factores ha sido utilizada con buenos resultados por algunos críticos para intentar desentrañar el pensamiento borgeano a través del análisis de su lenguaje. Entre las figuras predominantemente utilizadas por el autor están el oxímoron y la metáfora. El primero ha sido estudiado fundamentalmente por Alazraki y Arias Fernández, quienes han llegado a la conclusión de que su uso reiterado indica una profunda tendencia a fundir diversos hechos y objetos en grandes unidades, a sobrepasar las aparentes diferencias que presentan entre sí las cosas y sujetos concretos, para hacer ver la esencial unidad del mundo. A resultados parecidos llegan Navarro y Gertel en su análisis del papel que cumple la metáfora en Borges, la cual serviría para tratar de descubrir y mostrar las relaciones que se dan entre las diversas cosas del mundo. En todo caso, es claro que para él todo mecanismo lingü ístico debe estar al servicio del pensamiento, si es que no se desea caer en una escritura puramente decorativa y vacía de representaciones.

Borges pone en evidencia una y otra vez, y sus críticos hacen con él lo mismo, que ya que no dis- ponemos para pensar de otro instrumento que el lenguaje, éste determinará constantemente a aquél. Esta íntima relación ha sido también estudiada, de muy diversas maneras, por las escuelas analíticas de pensamiento. Los resultados de dichas investigaciones tienden en general a darle la razón al planteamiento borgeano del problema, si bien sus respectivas posiciones distan mucho de ser similares.

Pero al constante énfasis que pone Borges en esta relación que une pensamiento y lenguaje, no debe entenderse que ella se de de manera puramente mecánica, y que a determinado lenguaje corresponda necesariamente cierto tipo de pensamiento. En primer lugar es obvio, y él no lo ignora, que formas nuevas de pensamiento van introduciendo modificaciones en la manera de captar, entender y utilizar el lenguaje. Ya me referí brevemente a esto. En segundo lugar, el condicionamiento nunca es tal que impida cierta libertad individual: el lenguaje constituye un marco de referencia, no una camisa de fuerza. En tercer lugar, el lenguaje, por importante que sea, no es el único condicionante del pensamiento: factores tan variados como la educación y la clase social también tienen fuerte influencia en él. Borges es consciente de ello y habla, por ejem plo de la influencia que ha tenido su ceguera en su forma de percibir y entender el mundo. En cuarto lugar el lenguaje está, a su vez, determinado por la manera de percibir y pensar el mundo. No hay que perder de vista el hecho de que dicha manera varía de sujeto a sujeto, de época a época y de cultura a cultura. Estos cambios no son simplemente producidos por el lenguaje, sino que más bien son recogidos por él. El lenguaje mismo, así como su valoración, están en relación dialéctica con la percepción del mundo imperante. Hablando de la disputa entre realismo y nominalismo nos dice Borges: "para el realismo lo primordial eran los universales (Platón diría las ideas, las formas; nosotros, los conceptos abstractos), y para el nominalismo los individuos. La historia de la filosofía no es un vano museo de distracciones y de juegos verbales; verosímilmente, las dos tesis corresponden a dos maneras de intuir la realidad (15)".

No debemos por tanto, ni en este ni en ningún otro problema, atribuirle al autor simplificaciones y certidumbres absolutas de las que ha estado muy lejos. Una de las características principales de su pensamiento es plantear los problemas con toda la profundidad que le es posible, no lle- 
gando en muchos casos a soluciones que considere satisfactorias. No tenemos, leyéndolo, la impresión de estar ante un dogmático que expone sus afirmaciones para convencernos de ellas, sino más bien ante un pensador que nos cuenta sus puntos de vista para dialogar con el lector.

Siendo las relaciones entre lenguaje, pensamiento e intuición del mundo tan complejas, ¿hasta qué punto es válida la idea borgeana de que el lenguaje determina, en buena medida, al pensamiento? Hay que tomar en cuenta lo siguiente a la hora de responder la pregunta. Evidentemente, la mayoría de las personas se ajustan en un todo a la visión del mundo que han heredado con su lenguaje, con su cultura. En dichas personas habrá una clara adecuación de su pensamiento personal con el lenguaje recibido, ya que lejos de ser cuestionadores y creadores de pautas de pensamiento han hecho suyas, reproduciéndolas, las ya fijadas en el lenguaje. Pero aún en los casos en que ello no sucede, en los grandes pensadores, encontramos la tremenda influencia del lenguaje sobre el pensamiento. No hay nadie que rompa de manera total con su época, con la tradición cultural heredada, y aún en el caso de presentarse tal ruptura ello sería una respuesta ante los patrones de pensamiento que se rechazan. Esto ayuda a explicar porque los diversos pensadores de una época, por diferentes que sean entre sí, tienen todos un mismo aire que los emparenta. Además todo pensamiento, por audaz, anticonvencional y revolucionario que sea, se expresará siempre en un lenguaje determinado, que lo condicionará en buena parte. Recodemos que Borges no ha afirmado ni que el lenguaje es el único factor que determina al pensamiento, ni que hay una relación mecánica entre ambos. Lo que él ha planteado, y creo que con toda razón, es la fuerte influencia que sobre todo pensamiento acarrea el inevitable uso del lenguaje.

Con respecto a que éste posibilita al pensamiento, empiezo aclarando que, al igual que no se plantea una relación mecanicista de determinación entre ambos, tampoco se planteará tal tipo de relación a nivel de su posibilidad. La presencia del lenguaje no posibilita, por sí sola, la existencia de auténtico pensamiento. Tomemos el caso de Funes: "Había aprendido sin esfuerzo el inglés, el francés, el portugués, el latín. Sospecho, sin embargo, que no era muy capaz de pensar. Pensar es olvidar diferencias, es generalizar, abstraer. En el abultado mundo de Funes no había sino de- talles, casi inmediatos (16)". Tenemos aquí un caso hipotético en que, pese a la abundancia lingüística, el pensamiento es planteado como débil y casi inexistente. Obviamente, la culpa no está en el lenguaje sino en el sujeto, incapaz de abstraerse a lo concreto del mundo. Será esta posibilidad lo que el lenguaje facilite.

Creo que en el texto anterior se encuentra una de las claves del pensamiento borgeano. Se nos da allí una concepción de lo que para él es el pensamiento: selección, generalización, abstracción. Así concebida la actividad pensante, es claro el aporte del lenguaje para la realización de ella: proporcionar la herramienta que nos permita pensar. Es indudable, como vimos, que todo enunciado por exacto y detallado que sea será siempre incompleto en relación con la realidad aludida, incluyendo en esta realidad al pensamiento que origina y organiza al enunciado. Mientras que cada acontecimiento, y en esto ha insistido mucho Borges, entraña un gigantesco caudal de detalles y relaciones, el lenguaje nos permite expresar tan sólo un número muy limitado de ellos. Las razones son muchas, no siendo la menos importante que mientras la realidad es simultánea y total, el lenguaje es sucesivo y parcial. Todo enunciado implica una selección, la cual a su vez implica el descartamiento de innumerable cantidad de factores presentes en el hecho $y$ no en su formulación lingüística. Es por ello que Funes, imposibilitado de efectuar tal selección, no se conforma con ninguna de los idiomas que llegó a conocer, siéndole imposible, por otro lado, forjar uno lo suficientemente rico y exacto para expresar de manera adecuada su detallado mundo.

Vemos entonces como esta aparente pobreza del lenguaje permite, gracias a la selección y abstracción implícitos en él, al pensamiento. Borges está totalmente consciente, y esto es apuntado por algunos críticos, de que sin la simplificación que las ideas imponen el pensamiento, a como él lo entiende, sería imposible. Hay pues una actitud ambivalente ante este fenómeno de la abstracción lingüística. Por un lado está su queja de que por ser el lenguaje un instrumento deficiente, no sea posible expresar con él toda la increíble riqueza y variedad de pensamientos, cosas, experiencias y sentimientos individuales y concretos. Hay una profunda desconfianza, en la que se evidencia la influencia de Berkeley, hacia la capacidad del lenguaje para capturar y expresar el mundo mediante 
conceptos generales y abstractos como los que privan en aquél. Claro está que en esto, como en todo, es posible encontrar situaciones y matices que parecen estar en contradicción con las ideas generales aquí esbozadas, y Borges así lo plantea. Por ejemplo, en su afirmación de que lo genérico puede ser más intenso que lo individual, o en la idea que apunta en sus primeros libros de que una representación muy simple puede ser el sujeto de un enunciado muy complejo. Nótese sin embargo que tanto en el primer caso como en el segundo, todo enunciado debe haber sido pensado, previa o simultáneamente a su enunciación, con una complejidad que en el menor de los casos será igual a la que porte. También se podría objetar que un enunciado pensado por quien lo enuncia como simple, puede ser pensado por otro con una mucho mayor riqueza. La obra misma de Borges podría servir tal vez como ejemplo. De acuerdo, pero esto no varía la situación, ya que el enunciado, independientemente de los sujetos que lo crean y recrean no tiene poca o mucha riqueza, y si bien es cierto que puede ser el origen de otros muchos, estos deben a su vez haber sido pensados con al menos tanta complejidad como la que portan, con lo cual se vuelve al punto de partida.

Por otro lado hay un indudable reconocimiento de que, gracias casualmente a ello, es el lenguaje quien posibilita en buena medida al pensamiento. Aunque aquél nos imponga constantemente la ambigüedad, la inexactitud y el equívoco, nos sería imposible pensar si nos limitáramos a permanecer en la concreción de cada hecho individual. De esta necesaria e íntima conexión entre pensamiento y lenguaje, y tomando en cuenta las características ya apuntadas de éste, deriva parcialmente Borges su escepticismo ante la posibilidad de conocer el mundo; escepticismo que se extiende a la posibilidad de expresar con exactitud cualquier conocimiento alcanzado. No considera Borges posible ni que el pensamiento capte en su auténtica realidad el mundo, ni que el lenguaje pueda expresar exactamente nuestra relación con él. Lo anterior le ha hecho decir a Rest: "El pensamiento es, para Borges, siempre lenguaje, siempre discurso; y el lenguaje siempre es imperfecto, artificial (...) esto es lo que puso a Borges en el campo opuesto al platonismo, que a partir de nuestro intelecto pretendió erigir un orden metafísico válido, construido con ideas puras. Borges reconoce que nuestro bagaje de co- nocimientos consiste en una acumulación de ideas, pero ese mismo motivo lo empuja a negar la validez que se pretende conferir a tal conocimiento (17)".

Lo anterior implica que pese a ser el lenguaje una organización, una interpretación del mundo, no se podrá nunca tener la certeza de que ella responde a su auténtica realidad, de que lo exprese adecuadamente. Antes bien, las características inherentes al lenguaje parecieran negar de plano la posibilidad misma de que tal cosa suceda. Es claro que si tomamos el lenguaje como una simplificación, necesaria e inevitable, tenemos que llegar a la conclusión de que esta simplificación implica siempre, de una u otra manera, no sólo un empobrecimiento y una esquematización sino, lo que es más grave, una deformación. A esto llega efectivamente Borges, quien lo plantea en varias ocasiones de manera explícita, como durante su entrevista con Charbonier. Casualmente el tomar conciencia de lo anterior es lo que hizo a Borges desistir de su tempranero intento por lograr un lenguaje que le permitiera una adecuada expresión de la realidad, optando en adelante por limitarse a su alusión. Con lo cual entramos de lleno en uno de los temas que más han apasionado a Borges: el de la relación entre lenguaje y realidad.

Lo que primero salta a la vista en este tema, siendo por ello lo que más han enfatizado sus críticos, es la concepción del lenguaje como un sistema arbitrario de símbolos, independiente de la realidad externa, que tenderá a falsearla. Tal punto de vista es planteado adecuadamente en el libro de Echavarría. No hay, se afirma, ninguna relación clara y mucho menos necesaria, entre los signos lingüísticos y sus significados. La única excepción a lo anterior podría estar constituída por las palabras onomatopéyicas, pero ellas son una insignificante minoría. Mientras la realidad se nos presenta en la forma de una infinita cantidad de hechos concretos, el lenguaje pretende que todos ellos encuentren expresión en un limitado conjunto de signos arbitrarios, en donde predominan los conceptos generales y abstractos. Una de las citas utilizadas con preferencia por Borges es de Chesterton, quien afirma: "El hombre sabe que hay en el alma tintes más desconcertantes, más innumerables y más anónimos que en una selva otoñal. Cree, sin embargo que esos tintes, en todas sus fusiones y conversiones, son representables con precisión por un mecanismo arbitrario de gruñidos y de chi- 
llidos. Cree que del interior de un bolsista salen realmente ruidos que significan todos los misterios de la memoria y todas las agonías del anhelo... (18)". La conclusión es clara: es imposible expresar, mediante el lenguaje, la interminable riqueza de la realidad. El lenguaje será siempre una arbitraria simplificación, una abstracción empobrecida. Sin embargo, estamos obligados a su uso, no podemos pensar y expresar la realidad si no es a través del lenguaje, cualquiera que éste sea. Además, por muy simplificada y distorsionada que sea la imagen del mundo contenida en el lenguaje, es indudable que ella existe. ¿Cuáles serán, pues, las relaciones que se den entre realidad y lenguaje? Grandes esfuerzos ha dedicado Borges a meditar sobre este tema.

Una primera observación la constituye la constatación de las diversas posibilidades de entender dichas relaciones. Obviando los múltiples matices que ha suscitado la cuestión, encuentra Borges dos posiciones básicas, de las cuales nos dice lo siguiente: "Observa Coleridge que todos los hombres nacen aristotélicos o platónicos. Los últimos sienten que las clases, los órdenes y los géneros son realidades; los primeros, que son generalizaciones; para éstos, el lenguaje no es otra cosa que un aproximativo juego de símbolos; para aquéllos es el mapa del universo (19)". Salta a la vista algo que ya se había notado en su observación sobre la polémica realismo-nominalismo: la influencia que ejercen entre sí la manera de percibir la realidad y de valorar el lenguaje. Tan lícito es hablar de que là valoración del lenguaje está fuertemente influida por la manera de percibir la realidad, como referirse a la influencia que sobre la percepción del mundo tiene nuestra manera de entender el lenguaje.

De las dos posiciones expuestas, considero lícito ubicar a Borges en la así llamada aristotélica. Conviene empero no darle demasiada importancia a esta denominación, que podría llevar a confusiones, y aventurarse más bien en lo que él ha dicho sobre el tema. El respecto, su afirmación básica es la imposibilidad de establecer una relación de igualdad entre lenguaje y realidad, la imposibilidad de considerar que ésta esté incluida en aquél. Una primera comprobación, evidente pero no por eso siempre tomada en cuenta, es el hecho de que la realidad no es verbal. Esta diferenciación, en apariencia tan obvia, no siempre es constatada o admitida por quienes han estudiado el pensamiento borgeano, del cual se ha dicho por ejemplo que anula la realidad, sustituyéndola por un mundo puramente lingü ístico. Creo que en Borges, por complejas y ambiguas que puedan ser las relaciones entre lenguaje y realidad, éstas se mantienen como tales: como relaciones entre dos términos que no pueden ser reducidos el uno al otro. Podría, cosa que de hecho sucede, considerarse al lenguaje como parte de la realidad, pero nunca a ésta como reducible a aquél.

Siempre enfatizando esta diferenciación, afirma Borges: "Lo que Ilamamos realidad viene a ser un conjunto de percepciones, de emociones, de encuentros, de pensamientos, de sueños, de distracciones, de sorpresas, esa es la realidad. En cambio, el idioma es un sistema rígido (20)".

Esta mayor rigidez y simplicidad del lenguaje con respecto a la realidad se manifiesta de diversas maneras, siendo señalada constantemente por Borges. No son raros los cuentos en que se aclara explícitamente que la realidad narrada fue mucho más compleja que la narración, o que ésta es un mero resumen, o que está incompleta por falta de información, etc. Se alude también a la gran diferencia entre los conceptos y la compleja realidad que señalan, como en el poema "La noche que en el Sur lo velaron", en donde nos habla de la muerte, "-misterio cuyo vacante nombre poseo y cuya realidad no abarcamos- (21)", etc. No importa cuan precisas y exactas sean las palabras empleadas, éstas nunca podrán dar cuenta completa de la realidad.

"Sé que las palabras que dicto son acaso precisas, pero sutilmente serán falsas, porque la realidad es inasible y porque el lenguaje es un orden de signos rígidos (22)".

afirma en "East Lansing". Whitehead, dice Borges, ha hecho bien en denunciar la falacia del diccionario perfecto, en donde para cada cosa habría una palabra. El trabajo con el lenguaje será por tanto siempre un trabajo a tientas.

Otra característica, ya mencionada, que imposibilita la identificación lenguaje-realidad es que mientras aquél tiene siempre un carácter sucesivo, dicho carácter no siempre corresponde a la realidad. Así, es imposible expresar adecuadamente mediante el lenguaje lo simultáneo de una visión, de una percepción (cf. "El aleph"); o razonar con exactitud lo eterno, lo intemporal (cf. "Nueva refutación del tiempo"). Por todo lo anterior Borges concluye que el lenguaje no corresponde con exactitud a la realidad, que no son sinónimos. La relación, por tanto, entre realidad y lenguaje no 
será de igualdad; sin embargo no es esta la única posible. Lo que será imposible mediante el lenguaje es expresar con toda exactitud y detalle a la realidad; pero renunciando a esta pretensión podemos encontrar medios para referirnos, con mayor o menor exactitud y riqueza, a ella. Algunos críticos, en vista del rechazo de la posibilidad de expresión exacta de la realidad, de la desigualdad entre ésta y el lenguaje, han afirmado que en Borges se da una imposibilidad total de referirse al mundo mediante el lenguaje. Yurkievich, por ejemplo, afirma: "Para Borges, lenguaje y mundo no son equivalentes, no son intercambiables. Para Borges el mundo (...) es definitivamente inintelegible; esta infinita e indivisa, esa ubicua y simultánea totalidad es directa, alegórica o simbólicamente indecible (23)". O sea, que de la diferenciación clara y definitiva en Borges, entre lenguaje y realidad, se concluye la no existencia de ninguna relación entre ambos. Tal posición me parece indefendible.

Existen posibilidades de referirse lingüísticamente a la realidad. Más aún, no hay enunciado lingüístico, dirá Borges, que no aluda de alguna manera a la realidad. Eso fue lo que comprendió después de publicados sus primeros libros. A partir de entonces no buscará cómo expresar la realidad, sino cómo aludirla de la manera más conveniente.

Todo lenguaje implica una alusión a la realidad, no habiendo en esto diferencias entre uno y otro. Lo que variará será la manera de aludirla, que podrá ser más o menos directa, detallada, etc. De hecho, para él no habrá enunciado que no implique, no sólo la realidad aludida directamente sino, indirectamente, la totalidad del mundo. Lo anterior es planteado en cuentos como "La escritura del dios", y afirmado de manera explícita en el prólogo a $E l$ informe de Brodie, donde dice: "He intentado, no sé con que fortuna, la redacción de cuentos directos. No me atrevo a afirmar que son sencillos; no hay en la tierra una sóla página, una sóla palabra, que lo sea, ya que todas postulan el universo, cuyo más notorio atributo es la complejidad (24)".

Hay, entonces, una extraña dialéctica entre la imposibilidad de expresar directa y exactamente la realidad, y la inevitable alusión que a ella hace todo enunciado lingü ístico. Dicha posición irá siendo cada vez más explícita en su obra, en la cual, como bien lo ha observado Barrenechea, se da una cierta evolución al respecto. La primera etapa, a la que ya nos hemos referido, está marcada por un recelo radical ante el lenguaje, producto de la imposibilidad ya mencionada. A partir de aquí se irán acentuando los comentarios sobre la naturaleza diver- gente de realidad y lenguaje, con el consiguiente énfasis en el carácter de ficción que todo discurso encierra en sí. Es aquí donde la posición de Borges se separa, en forma definitiva, de la mantenida por los filósofos analíticos. En efecto, mientras aquéIlos, como afirma Rest, "tratan de superar la inadecuación del lenguaje con el propósito de perfeccionar un vehículo que facilite el acceso discursivo a la realidad, Borges reivindica esas mismas limitaciones que habían sido denunciadas y subraya la función protagónica que desempeña la ficción en el desenvolvimiento de cualquier especie de discurso (25)". Paralelamente a esto, Borges se irá conven ciendo cada vez más de que esta ficción, por fantástica que sea, no tiene otro origen ni otra referencia que la realidad, a la cual le será imposible no aludir; todo lo cual está en perfecta concordancia con sus ideas generales sobre el lenguaje. Esto ayuda a aclarar en que sentido he afirmado que las reflexiones de Borges, lejos de estar constituidas por una serie de ideas aisladas y sin desarrollo configuran, incluso a su pesar, una posición profunda y coherente ante los temas abordados.

Vale la pena, antes de continuar, hacer una observación a lo anterior. He dicho que la realidad no puede ser expresada de manera directa mediante el lenguaje: a esto hay que agregar que ello no impide aludirla de manera directa, aunque simplificada y resumida. Tal cosa ocurre por ejemplo en "Tlön, Uqbar, Orbis Tertius", en donde el hallazgo, parcial primero y total después, de la enciclopedia sobre Tlön permite a los hombres conocer su historia, arquitectura, fauna, metafísica, etc. Es claro que dicha obra no puede transmitir un conocimiento completo y exacto de la supuesta realidad total del planeta, pero sí plantea un resumen lo suficientemente riguroso y detallado como para conjeturar qué tipo de planeta es Tlön.

El siguiente problema que se plantea deriva de lo dicho anteriormente, $y$ ha sido abordado por Borges, quien como buen discípulo de Berkeley cree que nosotros entramos en contacto directo, a través de los sentidos, con el mundo externo. Sin embargo, para pensar y expresar dicho mundo necesitamos recurrir al lenguaje, el cual es una interpretación y una simplificación de él, pero no su espejo. ¿Qué grado de influencia tendrá entonces el lenguaje, así como los ordenamientos e interpretaciones en él contenidos, sobre nuestra imagen del mundo? Podría parecer en un principio que la respuesta a esta pregunta es variable, dependiendo de la percepción del mundo y la valoración del lenguaje de que se parta, pero la respuesta borgeana es 
un ívoca: toda imagen del mundo estará fuertemente influida por el lenguaje, independientemente de la posición que se tenga al respecto.

Analizando su planteamiento, vemos que se introduce en él, en cuanto a las formas de ordenamiento del mundo, una gran variabilidad que no encontramos en respuestas que aceptan la existencia de categorías innatas ordenadoras, como sería el caso de Kant. Según éste, interpretamos el mundo externo en base al aparato apriorístico presente en todo ser humano. Dicho aparato, compuesto por las formas a priori de la sensibilidad y las categorías, hace que haya un conjunto de conceptos $y$ parámetros ordenadores común a todos los hombres. En Borges tal aparato ordenador, en vez de ser invariable y común como en Kant, es el variable y diverso lenguaje. No en vano ha confesado haber sido derrotado en todos sus intentos por comprender al pensador alemán.

Para el argentino, la realidad se presenta como un conjunto caótico de percepciones, sentimientos, anhelos, etc. Es todo aquello que percibimos, de uno u otro modo. Ahora bien, mientras para Kant ese caos sensorial es ordenado de manera inmediata gracias al aparato apriorístico; para Borges este proceso ordenador se dará gracias al lenguaje. Ya que es imposible, si queremos tener una imagen ordenada del mundo, no utilizar el lenguaje, es claro que no podemos contruirnos ninguna imagen pura, por así decirlo, de él. Lo único que podemos saber de manera directa acerca de éste es que está ahí, constituido por un innumerable conjunto de entes concretos. Ya la clasificación de nuestras percepciones en provenientes de cosas y de hechos, por ejemplo, implica un ordenamiento, que no es entregado por la realidad misma.

Es claro, entonces, que toda imagen del mundo, todo ordenamiento y teorización que introduzcamos en él, estarán en buena medida determinados por el lenguaje. Aún los conceptos más básicos con que nos orientamos en la realidad, están determinados en buena parte por él. Esta influencia aparece en innumerables lugares de la obra borgeana, como en "El Golem", donde dice:

\footnotetext{
"Gradualmente se vio (como nosotros)

Aprisionado en esta red sonora

De Antes, Después, Ayer, Mientras, Ahora, Derecha, Izquierda, Yo, Tu, Aquéllos, Otros (26)"
}

Lo que según Borges podrá variar no es tanto el grado de influencia que sobre nuestra imagen del mundo tenga el lenguaje, sino el grado de conciencia que tengamos respecto a ella, que es en sí inevi- table. Si la ignoramos, creeremos que nuestra imagen del mundo es un espejo fiel de éste; si estamos conscientes de ella sabremos que es tan sólo un ordenamiento, entre muchos posibles, y que no agota a la realidad. Para Borges el distanciamiento entre mundo y lenguaje no es total; simplemente que cualquier orden que establezcamos no es necesario sino posible; pero nunca será necesariamente falso. Todo ordenamiento del mundo debe corresponder, en mayor o menor medida, al inagotable mundo. En este sentido no se llega a postular ningún mundo de cosas en sí, totalmente aislado e incognoscible. Nunca alcanzaremos un conocimiento total y exacto de la realidad no vei hal que nos circunda, y de la cual somos parte, pero estamos siempre en contacto con ella y podemos aludirla a través del lenguaje. De hecho, es tal la influencia que sobre nuestra percepción de la realidad tiene éste, que incluso podemos tratar de moldearla en base a mecanismos lingüísticos, que pueden acabar por configurarla. Leemos en "La muralla y los libros": "Quizá el Emperador quizo recrear el principio del tiempo y se llamó Primero, para ser realmente el primero, y se llamó Huang $\mathrm{Ti}$, para ser de algún modo Huang $\mathrm{Ti}$, el legendario emperador que inventó la escritura y la brújula (27)".

Dos características del lenguaje: la gran influencia sobre nuestra imagen de la realidad y la inevitabilidad de su uso, llevan al problema de la supuesta asimilación de lo real por el lenguaje. Este problema, al mismo tiempo que ha sido ampliamente tratado en la obra de Borges, es uno de los que más interés ha suscitado en la crítica. Hemos visto que Borges afirma claramente el carácter no verbal de la realidad. De la misma manera afirmará el carácter puramente lingüístico de toda manifestación del lenguaje. Todo enunciado lingü ístico será, con respecto a la realidad no verbal, ficción, y ello independientemente de su tipo de relación con la realidad a la que, necesariamente, aludirá. Si todo enunciado lingü ístico es en última instancia ficción, ello implica que en el momento en que la realidad es incluida en ellos abandona su carácter de tal y se vuelve también ficción: el lenguaje convierte en ficticio todo cuanto toca. Esta condición, en apariencia $\tan$ extraña, es afirmada sin titubeos por Borges. Así, en "El otro tigre", escribe:

\footnotetext{
"Cunde la tarde en mi alma y reflexiono

Que el tigre vocativo de mi verso

Es un tigre de símbolo y sombras,

Una serie de tropos literarios

$Y$ de memorias de la enciclopedia

$Y$ no el tigre fatal, la aciaga joya
} 
Que, bajo el sol o la diversa luna,

Va cumpliendo en Sumatra o en Bengala

Su rutina de amor, de ocio y de muerte.

Al tigre de los símbolos he opuesto

El verdadero, el de caliente sangre,

El que diezma la tribu de los búfalos

Y hoy, 3 de agosto del 59 ,

Alarga en la pradera una pausada

Sombra, pero ya el hecho de nombrarlo

$Y$ de conjeturar su circunstancia

Lo hace ficción del arte y no criatura

Viviente de las que andan por la tierra (28)".

Tenemos dos campos claramente definidos: lenguaje y realidad no verbal. El primero tiene sus leyes propias, una de las cuales es que todo lo que penetra en su ámbito adquiere su característica principal: ser ficción en relación con lo no verbal. De esto podemos suponer que también tiene sus leyes propias, sólo que a la hora de conjeturarlas y expresarlas éstas adquirirán carácter de ficción por lo ya dicho. La relación entonces entre lenguaje y realidad no verbal podría parecer totalmente desequilibrada: mientras la realidad se convierte necesariamente en ficción a la hora de ingresar en el lenguaje, éste nunca se convierte en otra cosa que en lo que es en sí mismo: lenguaje. Sin embargo, según mi interpretación esto no es así. En primer lugar todo lenguaje por el mero hecho de existir pasa a ser parte de la realidad en general, a la cual pertenecen tanto la verbal como la no verbal. Por otro lado la realidad no verbal, por ser la que en última instancia lo origina, jamás dejará de estar presente en el lenguaje. Todo enunciado, por ficticio y fantasioso que sea deberá aludir a la realidad no verbal, si es que ha de tener algún sentido. Así, todo lenguaje estará obligado a postular, aún sin quererlo, al mundo que lo origina. Vemos entonces que las relaciones entre lo verbal y lo no verbal son más complejas de lo que parecieran a simple vista.

Una buena parte de los críticos no comparten tal perspectiva, y sostienen que en Borges lo que se plantea es una supremacía total del lenguaje sobre la realidad. No se mantendría la diferenciación que he establecido sino que, en virtud de las relaciones ya enunciadas, toda realidad se convertiría en verbal. Esta posición es sostenida con alguna diversidad de matices. Por ejemplo, Guillermo Sucre planteará que, siendo el mundo que pensamos y expresamos el resultado de la actividad del hombre, su única fundamentación posible estará en la palabra. O el mundo entra en el lenguaje, afirma, o se ve reducido a la inexistencia, a un puro caos en donde el hombre mismo y la noción de mundo se aniquilan. Gerardo Goloboff va aún más allá al afirmar: "La palabra, como se ve, es una realidad muchas veces más potente que ta realidad misma; la nombra, la hace, la conforma, la deforma y también la deshace, porque la realidad es, finalmente, pura materia verbal (29)".

Borges ha sostenido que algunos escritores, como Whitman y Valéry, no sólo han forjado símbolos en su obra, sino que ellos mismos se han convertido en tales. Se ha querido ver en él también un símbolo: el del hombre perdido en un mundo de palabras, sin contacto directo con las cosas. Esta imagen es muy atractiva y muchos hechos ayudan a reforzarla: su ceguera, su desinterés en lo contemporáneo, su miopía política, sus ideas sobre el lenguaje. En una primera lectura de su obra, creí entrever dicha imagen, luego reforzada por muchos trabajos críticos; sin embargo, un conocimiento más en profundidad de su obra me ha convencido de lo contrario.

Creo que Borges, lejos de haber adaptado tal posición ha advertido, con la lucidez que le es característica en estos campos, acerca del peligro de llegar a identificar lo verbal y lo no verbal. Su planteamiento al respecto es el siguiente: podemos distinguir dentro de la realidad dos tipos de ésta: la verbal y la no verbal; usualmente se ha creído que la primera era un fiel reflejo, una expresión a grandes rasgos exacta y adecuada de la segunda. Pero esto no es así: ambas realidades, independientemente de las estrechas y complejas relaciones que se establecen entre ambas, no son asimilables la una a la otra. Hacerlo equivale a instalarse en el mundo más ordenado y humano de los dos, el verbal; pero equivale también a olvidarse de la irreductible realidad no verbal que nos rodea constantemente, de la cual hemos surgido, a la cual pertenecemos y la que, al cabo nos aniquilará. Establezcamos nuestros ordenamientos, nuestras interpretaciones lingüísticas de esa realidad, vivamos cómodamente en ellas, pero no olvidemos que existe otra realidad que es la fundamental.

Borges está plenamente consciente del gran influjo, de la fuerza de convicción que el lenguaje ejerce sobre nosotros, la cual amenaza constantemente con aislarnos en un mundo de palabras. Este fenómeno, tan estudiado hoy en día, es planteado constantemente por él. En "Utopía de un hombre que está cansado", el habitante del futuro con quien se encuentra el protagonista le dice a éste que la imprenta ha sido abolida, entre otras cosas porque hacía olvidar la realidad: "Las imágenes y la letra impresa eran más reales 
que las cosas. Sólo lo publicado era verdedero (30)".

Lo anterior nos lleva a una curiosa paradoja: mientras la realidad no verbal es, considerada en sí misma, autosuficiente, no lo es desde el punto de vista del hombre, que siempre necesitará del lenguaje para pensarla y expresarla.

$\mathrm{El}$ hombre, como lo han planteado algunos críticos en concordancia con Borges, se ha desterrado a sí mismo en un universo de palabras. Inconscientes de que éstas configuran un sistema desigual a la realidad que pretende designar, se han olvidado de las diferencias entre ambas. Hemos confundido ambos órdenes, y creyendo referirnos a la realidad hemos construido un mundo verbal independiente. Esta construcción, por otro lado, es inevitable: el hombre no puede resignarse a vivir en la caótica inmediatez de lo no verbal. No se trata por tanto de renunciar a construir ordenamientos verbales; se trata de estar conscientes del carácter ficticio, tentativo y arbitrario de ellos. Todo sistema filosófico que como el de Spinoza, ejemplo utilizado por Borges, pretenda atrapar en sí la realidad, ser una expresión cabal de ella, lleva a la suplantación. Un ejemplo de la actitud postulada por el autor la encontramos con frecuencia en él mismo, como cuando escribe:

"Es de noche. No hay otros. Con el verso Debo labrar mi insípido universo (31)".

O sea, se está consciente del carácter particular y arbitrario del mundo que se construye con la palabra. Actuar de otra manera será ingenuidad, será pretender vanamente la expresión de la realidad, cuando lo único que nos está permitido e impuesto es su alusión.

Tomando en cuenta su permanente carácter de ficción, su imposibilidad de expresar adecuadamente la realidad, ¿en qué sentido cree Borges que se puede hablar de verdad en el lenguaje? Un primer aspecto, que nos recuerda a Berkeley es el énfasis que se pone en lo inmediato de nuestro contacto con el mundo. Este siempre estará ahí, y no pueden aplicársele conceptos como los de falsedad y verdad; por lo que ellos regirán tan sólo en el campo del lenguaje y de sus relaciones con la realidad. Al respecto, su posición es la siguiente: Toda clasificación del mundo es arbitraria y conjetural; en este sentido en tanto entendamos por verdad una adecuación entre mundo $y$ lenguaje, ella nunca se alcanzará. Sin embargo, deben tomarse en cuenta tres hechos. Por un lado, la certeza de que no hay manera de penetrar el esquema último del universo (caso de existir tal cosa) no ha podido, ni debe, disuadirnos de planear esquemas explicativos de él, aún cuando los sepamos provisionales y arbitrarios. Por otro lado, siéndole al lenguaje imposible dejar de aludir en todo momento a la realidad, esta alusión podrá ejercerse de una manera tal que podamos denominarla 'verdadera'. Por último siendo la noción de verdad algo que está más allá de la realidad y que no se aplica a ella, sino tan sólo al lenguaje, es de esperar que haya sectores dentro de éste que puedan recibir tal clasificación, lo cual estará determinado en última instancia por la adecuada alusión que haga de la realidad. La verdad, por tanto, no consistirá en la perfecta adecuación del enunciado con el mundo, sino en su adecuada alusión. En este sentido, no habrá jamás una verdad absoluta, conviviendo siempre con cierto grado de falsedad impuesto por la simplificación, la arbitrariedad, etc., que todo lenguaje implica.

Dice en "Formas de una leyenda": "La realidad puede ser demasiado compleja para la transmisión oral; la leyenda la recrea de una manera que sólo accidentalmente es falsa y que le permite andar por el mundo, de boca en boca (32)". Por otro lado, el escepticismo de Borges en relación a las posibilidades de desentrañar el esquema del universo, así como la comunicación de lo experimentado, lo hacen juzgar los textos en base a otros valores que no sean el de verdad y falsedad. Comparando el Hamlet de Saxo Grammaticus con el de Shakespeare, opta decididamente por este último aduciendo que los dos posiblemente serán igualmente irreales, pero que el del segundo es mucho más vivido y complejo.

Cosas como la coherencia, la viveza, la complejidad y la capacidad de maravillarnos sustituirán en buena parte a los valores estrictamente cognoscitivos a la hora de juzgar un texto. Siendo imposible expresar con exactitud el mundo, así como no aludirlo, los sistemas filosóficos y religiosos, las escuelas literarias, etc., no diferirán tanto entre sí por su valor cognoscitivo como por características tales como las apuntadas. Ello, no obstante, no debe hacernos pensar en un esteticismo decandente, sino en un escepticismo esencial que no es tomado trágica sino lúdicamente.

Hemos seguido en este artículo las principales reflexiones borgeanas sobre el lenguaje, haciendo ver su profunda unidad. Debo hacer notar, sin em- 
bargo, que una comprensión más a fondo de la importancia de este tema en Borges, así como de las consecuencias que dichas reflexiones tienen en su pensamiento, exige verlo en relación a su posición ante otros dos temas fundamentales de su obra: el conocimiento y la literatura, lo que intentaré abordar en trabajos posteriores. Por ahora concluiré recordando que, pese a todas las limitaciones y deformaciones que nos impone el lenguaje, no disponemos de otro medio para pensar y expresar el mundo, para comunicarnos.

\section{CITAS}

(1) Borges. Obras Completas; Buenos Aires, Emecé, 1981,p. 1016.

(2) --- El idioma de los argentinos; Buenos Aires, M. Gleizer, 1928, p. 65.

(3) -- - Obras Completas; p. 858.

(4) cit. en Echavarría Ferrari Arturo. Lengua y literatura de Borges; Barcelona, Ariel, 1983, p. 55.

(5) Vázquez, María Esther. Borges: imágenes, memorias, diálogos; Caracas, Monte Avila, 1977, p. 108.

(6) Borges. Obras Completas; p. 1022.

(7) Ibid;p. 1081.

(8) Ibid; p. 708.

(9) Ibid; p. 746.

(10) Montecchia, M.P. Reportaje a Borges; Buenos Aires, Crisol, 1977, pp. 60-61.

(11) Echavarría Ferrari Arturo.op. cit., p. 15.

(12) Borges. El idioma de los argentinos; p. 71

(13) -- - . Obras completas; p. 435.

(14) Ibid; p. 653.

(15) Ibid; p. 746.

(16) Ibid; p. 490.

(17) Rest Jaime. El laberinto del universo (Borges y el pensamiento nominalista); Buenos Aires, Librería Fausto, 1976, p. 58.

(18) cit. en Borges. Obras Completas; p. 672.

(19) Ibid; p. 718.

(20) Borges para millones; Buenos Aires, Corregidor, p. 62 .
(21) Borges. Obras Completas; p. 88.

(22) Ibid; p. 1136.

(23) Yurkievich, Saúl. Borges - Cortázar: mundos y modos de la ficción fantástica; en Revista Iberoamericana, vol. 46, n. 110 - 111, enerojunio, 1980, p. 156.

(24) Borges. Obras Completas; p. 1021.

(25) Rest Jaime. op. cit.; p. 89.

(26) Borges. Obras Completas; p. 886.

(27) Ibid; p. 634.

(28) Ibid; pp. 824-825.

(29) Goloboff Gerardo. Leer Borges; Buenos Aires, Huemul, 1978, p. 86 .

(30) Borges. El libro de arena; Madrid, Alianza y Emecé, 1983 , p. 72.

(31) ----. Obras Completas; p. 1098.

(32) Ibid; p. 740.

\section{BIBLIOGRAFIA DE JORGE LUIS BORGES}

\section{Libros}

Borges J. L. Obras completas; 1923 - 1972, Buenos Aires, Emecé, 1974.

. Obra poética 1923 - 1977; Madrid, Alianza Editorial, 1983.

Hispánico, vol. 26, n. 303.

El idioma de los argentinos; Buenos Aires, M. Gleizer, 1928. 1975.

Prólogos; Buenos Aires, Torres Agüero, Borges para millones; Buenos Aires, Corregidor, 1978.

Poesía juvenil; en Meneses Carlos; Poesía juvenil de Jorge Luis Borges; Barcelona, Olañeta, 1978 . 
-. Borges, Oral; Buenos Aires, Emecé y Belgrano, 1979.

-_-_. La cifra; Madrid, Alianza, 1978.

--_- Siete noches; México, Fondo de Cultura Económica, 1982. cé, 1983.

Textos de revista no recogidos en libros 1933.

-. Elementos de preceptiva; en Sur, n. 7, --_. Los laberintos policiales y Chesterton; en Sur, n. 10. 1935.

-_-_. Las últimas comedias de Shaw; en Sur, no. $24,1936$. 1936.

-. Lawrence y la Odisea; en Sur, no. 25,

-_-_. "La amortajada" de María Luisa Bombal; en Sur, no. 47, 1938.

. La biblioteca total; en Sur, no. 59, 1939. 1939.

Joyce y los neologismos; en Sur, n. 62,

"R. Kipling. A Study in Literature and Political Ideas" de Edward Shanks; en Sur, n. 76, 1941. 1941.

. Fragmento sobre Joyce; en Sur, n. 77,

-_-_. Traducción de León Felipe del "Canto a mí mismo" de Walt Whitman; en Sur, n. 88, 1984.

- Respuesta a la encuesta entre los escritores; en Latitud, n. 1, 1945.

Palabras pronunciadas en la comida que le ofrecieron los escritores; en Sur, no. 142, 1946.

\section{BIBLIOGRAFIA SOBRE EL TEMA DEL LENGUAJE EN BORGES}

Alazraki, Jaime. Borges y el problema del estilo; en Revista Hispánica Moderna. n. 3-4, año 33, 1967. 1976.

(ed.) Jorge Luis Borges; Madrid, Taurus,

--- El texto como palimpsesto; lectura intertextual de Borges en Hispanic Review, vol. $52, \mathrm{n} 3,1984$.

-_-_. La prosa narrativa de Jorge Luis Borges; Madrid, Gredos, 1974.

Aubrum, Charles V. Borges y la crítica literaria; en Cuadernos Hispanoamericanos, n. 316, 1976.

Barone, Orlando (comp.). Borges - Sábato: Diálogos: Buenos Aires, Emecé, 1976.

Barrenechea, Ana María. Borges y la narración que se autoanaliza; en Nueva Revista de Filología Hispánica, vol. 24, n. 2, 1975.

Borello, Rodolfo. Estructura de la prosa de Jorge Luis Borges; en Cuadernos Hispanoamericanos. n. $165,1963$.

Borinsky, Alicia. Reescribir y escribir: Arenas, Menard, Borges, Cervantes, Fray Servando; en Revista Iberoamericana, vol. 41, n. 92-93, 1975.

Burgin, Richard. Conversations with Jorge Luis Borges; New York, Avon, 1970.

Carrizo, Antonio. Borges el memorioso (entrevistas), México, Fondo de Cultura Económica, 1983.

Charbonier, Georges. El escritor y su obra; México, Siglo XXI, 1970.

Echavarría Ferrari, Arturo. Lengua y literatura de Borges; Barcelona, Ariel, 1983.

Gertel, Zunilda. Cambios fundamentales en la poesía de Borges; en Cuadernos Hispanoamericanos, n. 245, 1970. 
. Borges y la creación literaria; en Atenena, año 45, vol. 170; n. 421-422, 1968.

--_- La metáfora en la estilística de Borges; en Hispania, vol. 52, n. 1, n. 1, 1968.

Borges y su retorno a la poesía; New York, Universidad de lowa, Las Américas Publishing Company, 1969.

Giordano, Enrique. El juego de la creación en Borges; en Hispanic Review, vol. 53, no. 3, 1984.

Goloboff Gerardo. Leer Borges; Buenos Aires, Huemul, 1978.

Iñiga Madrigal, Luis. Para una estética de Borges; en Dispositio, vol 2, n. 5-6, 1977.

Jitrik, Noé. Estructura y significado en Ficciones de Jorge Luis Borges; en Casa de las Américas, vol. 53, 1969.

Lusky, Mary. Jorge Luis Borges y su lucha con el lenguaje; en Cuadernos Americanos, vol. 190, no. $5,1973$.

Maldavsky, David. Un estudio estilístico sobre la transmutación intelectual de las experiencias vitales de la narrativa de J. L. Borges, en Humbolt, n. 56, 1975.

Mignolo, Walter y Aguilar Mora, Jorge. Borges, el libro y la escritura; en Cahiers du monde hispanique et luso-brésilien, n. 17, 1971.

Milleret, Jean de. Entrevistas con Jorge Luis Borges; Caracas, Mon e Avila, 1971.

Montecchia, M.P. Reportaje a Borges, Buenos Aires, Crisol, 1977.

Navarro, Joaquina. Jorge Luis Borges, taumaturgo de la metáfora; en Revista Hispánica Moderna, vol. 31, 1965.

Percas, Helena. Algunas observaciones sobre la lengua de Borges; en Revista Iberoamericana, vol. 23, 1958.

Pérez, Alberto. Realidad y suprarrealidad en los cuentos fantásticos de Jorge Luis Borges; Miami, Universal, 1971.
Pollmann, Leo. El espantoso redentor. La poética inmanente de Historia universal de la infamia; en Revista Iberoamericana, vol. 45, n. 108 -109, 1979.

Rasi, Humberto. Borges frente a la poesía gauchesca: crítica y creación; en Revista lberoamericana, vol. 40, n. 87 - 88, 1974.

El laberinto del universo. (Borges y el pensamiento nominalista). Buenos Aires, Librería Fausto, 1976.

Ricci, Julio. Borges y el lunfardo; en Hispanófila, no. 47, 1973.

Rodríguez-Luis, Julio. La nueva metáfora de la creación artística en el cuento de Borges; en Insula, n. 340, 1975.

Rodríguez Monegal, Emir. Borges como crítico literario; en Ia Palabra y el Hombre, n. 31, 1964.

Borges, hacia una lectura poética; Madrid, Guadarrama, 1976.

Sábato, Ernesto, Tres aproximaciones a la literatura de nuestro tiempo.

Scari, Roberto. Aspectos realista-tradicionales en el arte narrativo de Borges; en Hispania, vol. 57, n. 4, 1974.

Shumway, N. Borges y la estilística; en Cuadernos Americanos, vol: 226, n. 5, 1979.

Varios. 40 Inquisiciones sobre Borges; en Revista Iberoamericana (número dedicado a Borges), $n$. $100-101,1977$.

\section{BIBLIOGRAFIA ADICIONAL}

Berkeley, G. A Treatise concerning the principles of human knowledge; Indianapolis. Bobbs Merrill, 1979.

Schopenhauer, A. EI Mundo como voluntad y representación; Buenos Aires, Aguilar, 1960, I volumen. 
